\title{
Pareto Improvement through Unilateral Matching of Public Good Contributions: The Role of Commitment
}

\author{
Wolfgang Buchholz \\ Richard Cornes \\ Wolfgang Peters \\ Dirk Rübbelke
}

CESIFO WORKING PAPER NO. 4863

CATEGORY 1: Public FinANCE

JUNE 2014

An electronic version of the paper may be downloaded

- from the SSRN website:

- from the RePEc website:

- from the CESifo website:

www.SSRN.com

www.RePEc.org

www.CESifo-group.org/wp

\section{CESifo}




\title{
Pareto Improvement through Unilateral Matching of Public Good Contributions: The Role of Commitment
}

\begin{abstract}
When providing public goods through voluntary contributions, a donor may introduce unilateral matching in order to reduce underprovision of the public good and thus inefficiency. By itself, however, matching benefits the donor but harms the recipient. We apply Cornes and Hartley's aggregative game approach to provide a novel graphical explanation of this transfer paradox, and also show how it may be avoided by introducing a commitment device.
\end{abstract}

JEL-Code: H230, H410.

Keywords: voluntary public good provision, matching, commitment.

\author{
Wolfgang Buchholz \\ University of Regensburg \\ Germany \\ wolfgang.buchholz@wiwi.uni- \\ regensburg.de \\ Wolfgang Peters \\ European University Viadrina \\ Frankfurt (Oder) / Germany \\ peters@europa-uni.de
}

\author{
Richard Cornes \\ Australian National University \\ Canberra / Australia \\ richard.cornes@anu.edu.au
}

\author{
Dirk Rübbelke \\ TU Bergakademie Freiberg \\ Germany \\ dirk.ruebbelke@vwl.tu-freiberg.de
}

June 16, 2014

We gratefully acknowledge financial support from the German Federal Ministry of Education and Research, RECAP 15, FKZ 01LA1139A, and ECCUITY, FKZ 01LA1104B. 


\section{INTRODUCTION}

The voluntary contribution model predicts that such global public goods as climate protection will typically be underprovided. To overcome this underprovision and to attain a Pareto improvement the proposed standard solution is mutual cooperation, governed by an international environmental agreement. However, implementation of such agreements is hard to achieve. Unilateral action, particularly involving one-sided matching, may offer a way out of this dilemma. This approach envisages one group of countries subsidizing ('matching') the public good contributions of another group of countries, thus reducing the effective public good price facing the recipient countries and encouraging them to increase their contributions ${ }^{1}$. This paper applies Cornes and Hartley's (2007) Aggregative Game Approach (AGA) to analyze a unilateral matching scheme within a simple two-player framework in which player (country) $A$ commits to matching country $B$ 's contribution while $B$ makes no reciprocal commitment. We first show that, without further conditions, the recipient country $B$ will be harmed by one-sided matching, echoing Bergstrom's (1989) cautionary tale about paradoxical effects of transfers in a public-good economy (see also Roberts 1987 and Boadway et al. 1989). We exploit the AGA to provide an intuitive explanation for this 'puzzle' which identifies the two conceptually different channels through which the recipient is hurt. We then show how, by introducing a complementary commitment device, matching can also be made beneficial for the recipient country $B$, thereby rendering participation in the matching scheme individually rational for both countries.

\section{THE TRANSFER PARADOX THROUGH THE LENS OF THE AGGREGATIVE GAME} APPROACH

Country $i(i=A, B)$ has preferences over a private good $x_{i}$ and a pure public good $G$ represented by utility function $u_{i}\left(x_{i}, G\right)$ which is quasi-concave, everywhere increasing and twice continuously differentiable in both arguments. Both goods are everywhere normal.

We denote country $i$ 's exogenous income and unit cost of public good provision by $w_{i}$ and $c_{i}$ respectively. In the Nash games considered here, each country independently chooses its flat contribution to the public good $y i$. Denoting by $s$ the matching rate by which country $A$ sub-

\footnotetext{
${ }^{1}$ Various authors have extended Guttman's $(1978,1987)$ seminal analysis of reciprocal matching schemes and public good provision. Notable examples include Boadway et al. (2007) and Buchholz et al. (2011).
} 
sidizes country $B$ 's flat contribution $y_{B}$, the quantity $s y_{B}$ is a committed and thus compulsory public good contribution for $A$. The total public good contribution of country $A$ thus is $g_{A}=$ $y_{A}+s y_{B}$. Country B's total and flat contributions are identical, i.e. $g_{B}=y_{B}$. The budget constraints of $A$ and $B$ are therefore, respectively,

$x_{A}+c_{A} g_{A}=x_{A}+c_{A} y_{A}+c_{A} s y_{B}=w_{A}$

and

$x_{B}+c_{B} g_{B}=x_{B}+c_{B} y_{B}=w_{B}$.

Total public good provision at any feasible allocation is

$G=g_{A}+g_{B}=y_{A}+(1+s) y_{B}$.

Following the AGA, we describe the behavior of countries $i=A, B$ by their replacement functions which indicate how much of some total public good supply $G$ a country is willing to provide on a voluntary basis.

To characterize and locate Nash equilibria using replacement functions, consider first the standard Nash-case without matching, i.e. $s=0$. Here the Nash equilibrium $\mathrm{N}$ with public good supply $G^{0}$ is characterized by the consistency requirement

$$
G^{0}=r_{A}^{0}\left(G^{0}\right)+r_{B}^{0}\left(G^{0}\right)
$$

where $r_{i}^{0}(G)$ is the replacement function of country $i=1,2$ without matching (see Figure 1 ). The graph of $r_{i}^{0}(G)$ is the locus of all points in the $\left(G, y_{i}\right)$ - space where an indifference curve of country $i$ has slope one ${ }^{2}$. Given our assumptions on preferences the replacement functions are differentiable and given normality monotone decreasing in $\mathrm{G}$.

At the Nash equilibrium $\mathrm{N}$, country $i$ 's replacement function $r_{i}^{0}(G)$ intersects its feasibility line $e_{i}^{0}(G)=G-g_{j}^{0}$ : This 'budget line' shows how country $i$ ‘s public good contribution $g_{i}$ increases equally with total public good provision $G$ when country $j$ 's contribution is kept fixed at $g_{j}^{0}$.

\footnotetext{
${ }^{2}$ This condition clearly holds only at an interior allocation with strictly positive flat contributions.
} 


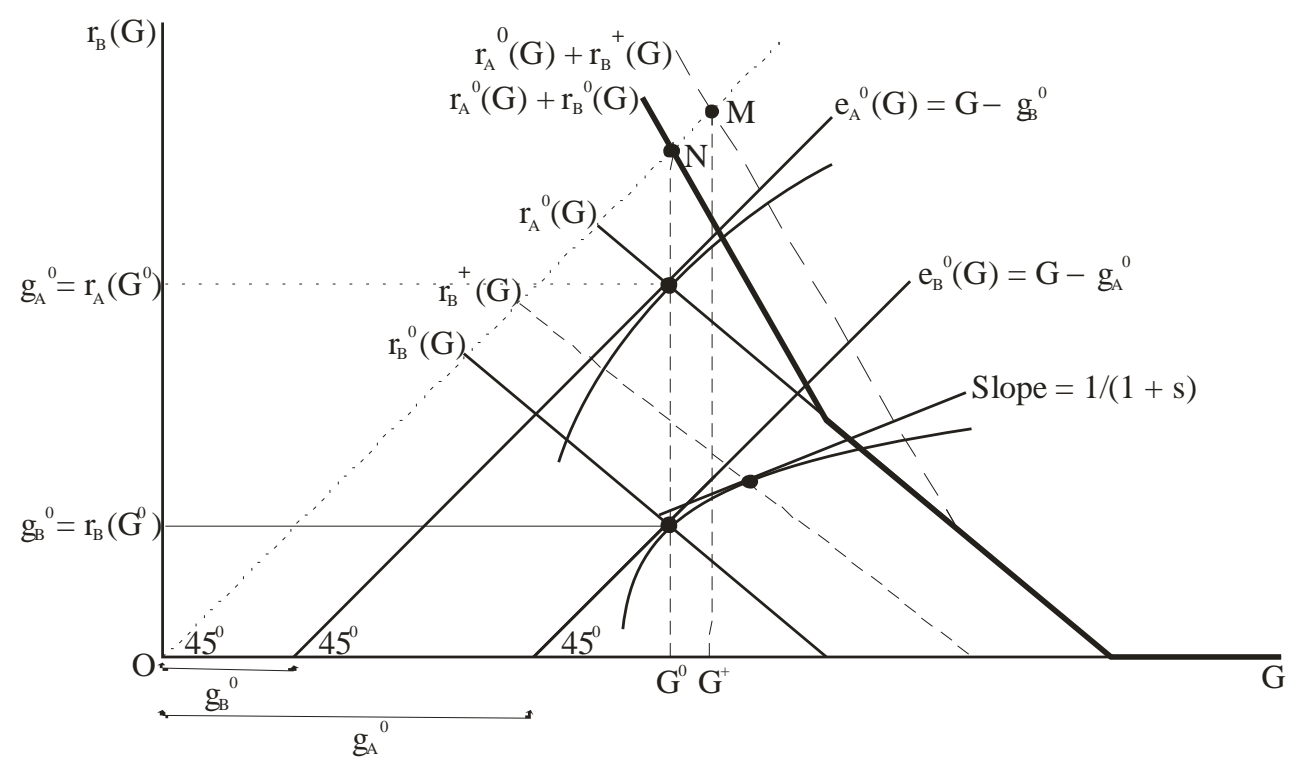

Figure 1: Nash equilibrium under zero and positive unilateral matching

We now consider the consequences of introducing a unilateral matching scheme, i.e. a discrete change of country $A$ 's matching rate from zero to some $s>0$. For country $B$, each increment of its flat contribution then is associated with an incremental increase in total public good provision of $1+s$ units. Country $B$ 's replacement function $r_{B}^{+}(G)$, which is relevant in the case of matching, represents all those points in the $\left(G, y_{B}\right)$ - space where country $B$ 's indifference curves have a slope of $1 /(1+s)$. This replacement function is graphed in Figure 1 by the dashed line. Country $A$, however, remains on its original replacement function $r^{0}(G)$. Under positive matching, the consistency condition for the Nash equilibrium with matching $\mathrm{M}$ becomes

$$
G^{+}=r_{A}^{0}\left(G^{+}\right)+r_{B}^{+}\left(G^{+}\right) .
$$

Note that - in contrast to Bergstrom (1989) and Boadway, Pestieau and Wildasin (1989) - this characterization of a matching equilibrium does not assume lump-sum financing of subsidy payments

We now compare the two Nash equilibria $\mathrm{N}$ and $\mathrm{M}$ assuming that both solutions are interior, i.e. that in equilibrium both countries make positive contributions. Since convexity of indifference curves entails $r_{B}^{+}(G)>r_{B}^{0}(G)$ for all $G>0$ and replacement functions are generally falling in $G$, a comparison of (4) and (5) gives $G^{+}>G^{0}$ and thus $r_{A}^{0}\left(G^{+}\right)<r_{A}^{0}\left(G^{0}\right)$, i.e. total public good supply increases while A's individual aggregate public good contribution falls. Thus, country A clearly benefits from the introduction of the matching scheme.

But condition (5) also implies that country B's public good contribution is increased by 
matching, i.e. $r_{B}^{+}\left(G^{+}\right)>r_{B}^{+}\left(G^{0}\right)$. Although it is not immediately clear how utility of the recipient country $B$ will change through matching, closer inspection shows the following result:

Proposition 1: The recipient country $B$ is made worse off through matching through two separate effects, a substitution and an income effect.

Proof. (a) Substitution Effect: We fix country A's total contribution at its initial value $g_{A}^{0}$, so that in Figure 2 country B's 'budget line' $e_{B}^{0}(G)$ is not changed. At the same time, matching implies a distortion of country B's relative public good price, which puts this country on the replacement function $r_{B}^{+}(G)$. The substitution effect shifts Country $B$ to the point of intersection D between $e_{B}^{0}(G)$ and $r_{B}^{+}(G)$ in which country $B$ has lower utility than in C. ${ }^{3}$

(b) Income effect: Country $A$ responds to $B$ 's higher public good contribution by reducing its own flat contribution, which follows since $A$ 's replacement function is downward sloping. In Figure 2 this causes a parallel shift of $B$ 's 'budget line' to the left from $e_{B}^{0}(G)$ to $e_{B}^{+}(G)$. The move from $\mathrm{D}$ to $\mathrm{E}$, which is $B$ 's equilibrium allocation with matching, generates a further loss for $B$.

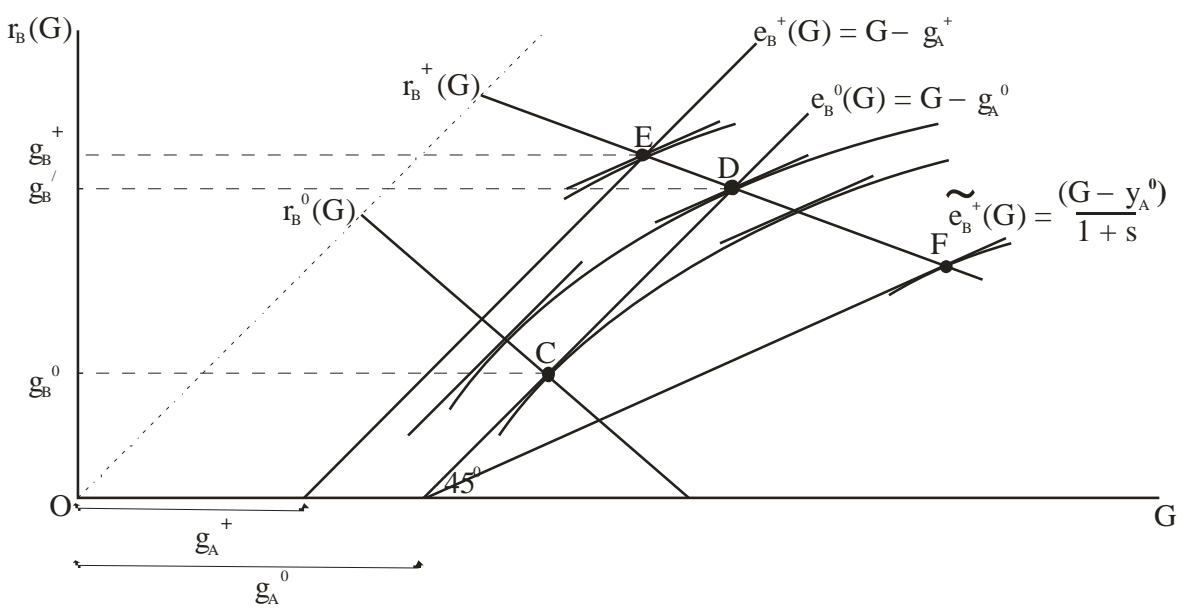

Figure 2: Recipient’s equilibrium utility response to matching without commitment

\section{COMMITMENT TO FLAT CONTRIBUTIONS IN THE DONOR COUNTRY}

The argument at the end of Section 2 confirms that recipient country $B$ loses even if the total public good contribution $g_{A}^{0}$ of the donor country A is held constant. Things, however, change

\footnotetext{
${ }^{3}$ This component of the total change, which keeps B's resource constraint unchanged while distorting the effective relative public good price facing it, is precisely what Cornes (1992, pp.100-101) calls an 'undercompensated price change'.
} 
completely if country A can stick to its flat contribution $y_{A}{ }^{0}$ associated with the original Nash equilibrium N. Complementing unilateral matching through such a stronger commitment device makes it not only possible to increase public-good supply to a greater extent than without matching but, under certain conditions, also to attain a Pareto improvement.

To show this we assume that the original matching equilibrium $\mathrm{N}$ is interior, i.e. $r_{i}^{0}\left(G^{0}\right)>0$ for $i=A, B$, and that country $A$ fixes its flat contributions at $y_{A}^{0}$, leaving country $B$ 's full income constant at $w_{B}+y_{A}^{0}$. The introduction of a positive matching rate $s$ now induces a clockwise rotation of country $B$ 's budget line which changes from $e_{B}^{0}(G)$ to $\widetilde{e_{B}^{+}}(G)=\frac{\left(G-y_{A}^{0}\right)}{1+s}$ (see also Figure 2). The change of the slope of country B's budget line from 1 to $\frac{1}{1+s}$ reflects the fact that an increase of $B$ 's flat contribution now is no longer crowded out by a reduction of $A$ 's flat contributions.

The outcome $\widetilde{M}$ with public good supply $G^{+}$then is given by country $B^{\prime}$ s optimal allocation on this budget line, i.e. by the point of intersection $F$ between $e_{B}^{+}(G)$ and $r_{B}^{+}(G)$. Country $B$ 's utility clearly rises, and from normality it follows that $\tilde{G}^{+}>G^{+}>G^{0}$. It remains to examine how utility of country $A$ changes in this case.

Proposition 2: The modified matching mechanism yields a Pareto improvement if it increases the recipient's public good contribution, i.e. if $\frac{\partial y_{B}}{\partial s}>0$.

Proof. Agent $A$ 's utility $u_{A}\left(w_{A}-c_{A} y_{A}^{0}-s c_{A} y_{B}, y_{A}^{0}+(1+s) y_{B}\right)$ depends on the matching rate $s$. Differentiating this expression w.r.t. to $s$ yields

$$
\frac{d u_{A}}{d s}=\left[\frac{\partial u_{A}}{\partial G}-c_{A} \frac{\partial u_{A}}{\partial x_{A}}\right]\left[s \frac{\partial y_{B}}{\partial s}+y_{B}\right]+\frac{\partial u_{A}}{\partial G} \frac{\partial y_{B}}{\partial s} .
$$

The first term on the right becomes zero for sufficiently small $s$. The second is positive if country $B$ increases its flat contribution - i.e. if $\frac{\partial y_{B}}{\partial s}>0$.

The condition $\frac{\partial y_{B}}{\partial s}>0$, which is fulfilled when the private and the public good are substitutes for country $B$, is essential to ensure a Pareto improvement as it excludes crowding-out behavior of country $B$.

Extending the reasoning above it can also be shown that welfare of both countries is definitely improved through unilateral matching if country A not only commits to its initial flat con- 
tribution $y_{A}^{0}$ but also restricts matching to public contributions of $B$ exceeding $y_{0}^{B} \cdot 4$

\section{CONCLUSION}

Our analysis confirms that, under fairly general conditions, mere unilateral matching increases the donor's welfare but reduces that of the recipient so that matching is not incentivecompatible in this case. This paradoxical situation, however, may be overcome by the additional application of a self-commitment strategy of the donor country so that a Pareto improvement is achieved through unilateral matching and no conflict arises between the donor and the recipient country.

\footnotetext{
${ }^{4}$ There is a notable circumstance that automatically imposes such a commitment on $A$ without the need for a formal agreement - this occurs when, at the initial Nash equilibrium with zero matching, $A$ 's valuation of the public good falls short of unity, so that $g_{A}^{0}=0$.
} 


\section{REFERENCES}

Bergstrom, T. (1989), Love and spaghetti, the opportunity cost of virtue, Journal of EconomicPerspectives 3,165 - 173.

Boadway, R., Pestieau, P. and D. Wildasin (1989), Tax-transfer policies and the voluntary provision of public goods, Journal of Public Economics 39, 157 - 176.

Boadway, R., Song, Z. and F.J. Tremblay (2007), Commitment and matching contributions to public goods, Journal of Public Economics 91, 1664 - 1683.

Buchholz, W., Cornes, R. and D. Rübbelke (2011), Interior matching equilibria in a public good economy: An aggregative game approach, Journal of Public Economics 95, 639 - 645.

Cornes, R.C. (1992), Duality and Modern Economics, Cambridge University Press.

Cornes, R.C. and R. Hartley (2007), Aggregative public good games, Journal of Public Economic Theory 9, 201 - 219.

Guttman, J. M. (1978), Understanding Collective Action: Matching Behavior, American Economic Review 68, 251-255.

Guttman, J. M. (1987), A Non-Cournot Model of Voluntary Collective Action, Economica 54, $1-19$.

Roberts, R.D. (1987), Financing public goods, Journal of Political Economy 95, 420-437. 